\title{
The Comparison between Tibetan Intangible Cultural Heritage Tibetan Opera and French Mime
}

\author{
Xiaoda Fan, Angwengzhuoma \\ Sichuan Minzun College, Kangding, Sichuan, 626001, China
}

\begin{abstract}
The human spirit world manifests although has each kind of difference in the culture, but mutually relates, forms the human splendid intangible cultural heritage together. Due to geographical differences, environmental differences and historical differences, the world's national culture showing a hundred flowers bloom. Taking Tibetan Opera and French mime as an example, this paper analyzes the similarities and differences between western culture and Tibetan traditional culture, which is one of the oriental cultures. From the comparison, it reveals the spiritual, religious, ancient, mysterious features of Tibetan traditional culture.
\end{abstract}

Keywords: Tibetan, traditional culture, western culture, intangible cultural heritage, Tibetan Opera, mime

\section{Introduction}

The intangible cultural heritage is the witness of a nation's history of creation, the cultural identity of a nation, the label of national spirit, the carrier of national wisdom and emotion, the precious historical wealth, and the traditional culture. People are beginning to pay attention to those who return to basics, on behalf of the national traditional culture of art, longing to find their own "where to" the source, as critics Gu Xiaoming's summary of "modern people looking for the loss of life, of the straw hat. Both at home and abroad, the government or the people are increasingly attached importance to the protection of intangible cultural heritage. 
The intangible cultural heritage of different ethnic groups embodies the cultural characteristics of different nationalities. Here we analyze the similarities and differences between the Tibetan traditional culture and the western culture, taking Tibetan opera and French mimesis as examples.

\section{The Tibetan intangible cultural heritage "Tibetan opera"}

\subsection{The protection of intangible cultural heritage in Tibetan areas}

By the end of 2010, there were altogether 60 national intangible cultural heritages, 222 intangible cultural heritages and 186 representative intangible cultural heritages in Tibetan areas, and also covered the five major categories of intangible cultural heritage classified by the United Nations Educational, Scientific and Cultural Organization Heritage and China's State Council announced the ten categories of intangible cultural heritage. Each category of intangible cultural heritage has complex and diverse forms of expression, such as the performing arts of the intangible cultural heritage of music, dance, drama, folk art and other forms of expression, each expression also contains different performance techniques, such as dance and Divided into folk dances and traditional dances, forms of expression can be described as colourful. The intangible cultural heritage of the Tibetan area is of high value, and some representative projects occupy an important position in the whole country and even in the world. At present, there are Tibet Autonomous Region mainly Tibetan and Gesar two were included in the UNESCO "human intangible cultural heritage representative list."

\subsection{The cultural characteristics of Tibetan opera}

Tibetan opera, in the Tibetan language is called "Aguilam," translated "fairy sister" means. Hegel once said: "Which nation has drama, it marks the nation to mature ... Drama is a national civilized product of the national life."

Tibetans, a well-developed ethnic group, have a complete system in terms of geography, culture, folklore and religion, because of their long and steep terrain, inconvenient transportation and less communication with the outside world. Tibet as a long-term in the snow-covered plateau of the human survival of the limit to create the excellent culture, the Chinese nation is also extremely valuable cultural resources of all mankind. It is one of the oldest operas in Chinese drama, and it is said that it has been performing for more than 1,000 years. Other major operas such as Peking opera, opera, Sichuan Opera, history is shorter than the Tibetan opera. Tibetan opera is the art of the plateau, the sound distant sonorous, is the singer of the overall strength of the input, full of rich feelings, melody beat, heroic melancholy, more full of vicissitudes, naturally into the plateau of the forceful and boldness. Its high-pitched wide-singing can hold people's hearts firmly, a meal of a Young, sometimes like a brook gurgling water, and sometimes as the Plateau Emotion of the blast: a tune, is to meet the listener soul The true 
temperament, so some people will listen to side dance side together. Combined with the mysterious magnificent Tibetan mask art, so that viewers in the audiovisual feel shocked in the shock of sentiment. This is the magic of Tibetan opera. Rong opera and Tibetan opera as one of the new historical drama "Princess Wencheng" was selected "national stage art project" one of the top ten repertoires. At the opening ceremony of the 2008 Beijing Olympic Games, the Tibetan opera "Auspicious Olympics" will be the basic elements of the traditional Tibetan opera in different schools of dance, singing, reading, drums and costumes. With its simple, long and unique artistic style, celebrating a grand celebration scene, people left a deep impression.

Tibetan opera comes from the Tibetan people's long-term practice of production and life, which reflects the unique way of production, life, morality, emotions, likes and dislikes of Tibetan people, Tibetan folk songs, folklore, life, Strong national colours. Is a snow-covered plateau on the history of the nation, is the national progress and development of the "live" witness.

\section{The French intangible cultural heritage "mime"}

\subsection{French intangible cultural heritage protection}

France is a cultural heritage power, there is no cultural heritage from generation to generation and the French culture will be eclipsed. France is also a pioneer in the protection of cultural heritage, it is the world's first to develop modern cultural heritage protection law of the country, has a perfect cultural heritage management system and laws and regulations. The protection of the intangible cultural heritage of France is to start from the protection of material cultural heritage, in 1793, when many ethnic groups, regions have not yet aware of the importance of cultural heritage, and then to take protective measures, France has developed a "republic Two-year statute "which clearly states that all works of art in French territory are protected by the State. Since then, France has promulgated a series of cultural heritage protection law, such as "Monument Protection Law", "Historical Relics Architecture and Natural Landscape Protection Act", "Historical Monuments Law" and so on. As a result of the French government a series of measures, makes the French intangible cultural heritage protection thought thorough popular feeling, the populace formed the intense cultural protection idea, therefore the French tangible and the intangible cultural heritage has received the very good protection. In addition, France attaches importance to promoting the introduction of cultural heritage, cultural heritage play social and cultural role. France's protection of intangible cultural heritage should be said that in Western countries has a strong representation.

\subsection{The cultural features of mime}

Mime should be said that the French intangible cultural heritage in a more representative example, the first century $\mathrm{BC}$, mime was born in ancient Rome, 
the 18th century mime has become the most popular form of the British drama, followed in France to flourish. Mime in the process of performing the actor cannot speak, the performance of the actors through the body movements to express, but can make laughter, crying, some of the plot can also be completed through the narration is "to replace the body language action" in the form of drama, On the stage purely with gestures, body movements, facial expressions to interpret the drama, the spiritual outlook is its fundamental, with very little music, the rest is the performer's face waves, interpretation of the performer's understanding of life and life, Manifested in every detail of his body.

\section{The cultural similarity of intangible cultural heritage "Tibetan Opera" and "mime"}

The similarities and differences between the mimesis and the Tibetan opera are obvious, and the common features are the endless life experiences elaborated by the body language. Tibetan opera dances such as "L" and "D" show the performers or the sad Or hi mood and love of life, mime a twist, a turn, a look, simple but there is a huge appeal, led the audience's endless imagination. Tibetan drama and mime is the biggest difference is that in addition to music, dance, it is outside the language, singing and dialogue and singing dialogue means both have, and performance is an extension of language. The following we through cultural analysis to compare the Tibetan traditional culture and Western culture of the similarity, analysis of intangible cultural heritage embodied in the commonality of national culture.

\subsection{The cultural groups}

The formation of intangible cultural heritage is inseparable from the collective, ca not be separated from the group, most of the daily life of the bits and pieces summarized as art, culture, it is group of sunrise, sunset and life scenes to The creators to inspiration, reproduce their production and life patterns, the formation of a culture, over time formed a national characteristics, from generation to generation. Through constant practice of the group, intangible cultural heritage can be produced and developed in group activities. This is the non-material cultural heritage to form the first condition is the group's awareness. At the same time, it is precisely because the group's awareness, only the culture of constant innovation, change and spread, will there be intangible cultural heritage possible. We take the origins of Tibetan opera as an example. Tibetan opera can be traced back to the primitive society. During the period of hunting, sowing, and harvesting, the dance of respecting nature is expressed. These sacrifices are later applied to the productive labour process. They express their understanding of production. The joy and hard work, is a unique Tibetan national social history and life in the soil to grow up, formed with its own unique style of art forms and charm. 


\subsection{The cultural heritage}

Intangible cultural heritage from generation to generation, with cultural heritage, which means that a group formed to become a unique culture inherited from generation to generation, the extension of time for the deferred and the transfer of groups, the initial intangible cultural heritage For the oral tradition, there are clear inheritors and inheritors, such as the Tibetan folk hero epic "Gesar soil" of rap, there is specialized in rap storytellers and singers. These rappers from generation to generation inheritance "Gesar soil" rap, Tibetan culture is also passed down from generation to generation. Inheritance continued to join the new group values, outlook on life and ethics, to meet the psychological needs of groups, reflecting the spirit of the community in general.

\subsection{The regional culture}

The intangible cultural heritage is closely related to the regional environment and language status of specific ethnic groups, showing a distinct regional character. Not the same geographical environment, there is no exactly the same culture. Culture, whether it is generated or circulated with a certain geographical association. For example, China's Spring Festival, after the Chinese people's esteem and time evolution, has not only is a major festival in people's lives, and become a symbol of Chinese culture.

\section{The cultural differences between intangible cultural heritage "Tibetan Opera" and "Mime"}

\subsection{The focus of cultural groups is different}

Aristotle's imitation constitutes the starting point of Western culture, Western art performance is the objective world of in-depth observation, and on this basis to accurately depict, focusing on the external restoration of the type of reproduction, emphasizing the accuracy And objective, art history is attached to the social history, so it is fundamentally material. For example: the origin of Tibetan opera, and religious rituals and religious art are closely related. The Tibetan History and Culture Dictionary describe the origins of Tibetan opera as "Tibetan opera originated from Buddhist rituals", and most of the deductions are Buddhist stories.

\subsection{Religious culture is different}

In Western religions, the godhead is almost equal to the personality, the mythical world and people's real life are closely linked, they recognized the projection of God, the longing of the world of God is also the reproduction of human life, and thus attach importance to Western art of personal feelings and The creativity of the individual; the protagonist of the religious art of the Tibetan area is the Buddha, the godhead and the personality have the essential difference, the 
Buddhist world and the reality of this world completely disengaged, emphasizing the reincarnation, Tibetan art embodies collectivism and mysticism Of creation. Therefore, the Tibetan traditional culture and the Western culture also has religious elements, but the religious implication is very different, thus showing the religious worship, religious culture also have differences.

\section{Conclusion}

The mankind spiritual world manifests has its unique characteristics in culture. Though it is different, it links with each other and forms the splendid legacy of human culture. Due to geographical differences, environmental differences and historical differences, the world's ethnic culture flourishes, showing the different aspects of the human spirit, forming different styles, each with a form of cultural carrier. As one of the oriental cultures, the Tibetan traditional culture shows its spiritual, religious, ancient and mysterious characteristics compared with the western culture.

\section{References}

[1] Huang Saifeng. Government-led protection of intangible cultural heritage in Tibet, Tibet University, 55(12), pp.68-70, 2011

[2] Li Yun, Zhou Quangen. Tibetan opera, Zhejiang People's Publishing House, 8 (5), pp.87-91, 2013

[3] Zheng Li. Tibetan legal protection of the study, China University of Political Science, 12(10), pp. 18-20, 2012

[4] Huang Saifeng. Government-led research on the protection of intangible cultural heritage in Tibet, Tibet University 9(6), pp.58- 61, 2011

[5] Li Mosi. Intangible cultural heritage protection law research, East China University of Politics and Law, 8(4), pp.85-87, 2014 